\title{
Epigenetic regulation of human buccal mucosa mitochondrial superoxide dismutase gene expression by diet
}

\author{
Roman Thaler ${ }^{1}$, Heidrun Karlic ${ }^{2,3}$, Petra Rust ${ }^{1}$ and Alexander G. Haslberger ${ }^{1} *$ \\ ${ }^{1}$ Department of Nutritional Sciences, University of Vienna, Althanstrasse 14, A-1090 Vienna, Austria \\ ${ }^{2}$ Ludwig Boltzmann Institute for Leukaemia Research, Hanusch Krankenhaus, Vienna, Austria \\ ${ }^{3}$ Hanuschkrankenhaus der Wiener Gebietskrankenkasse, Heinrich Collinstraße 30, A-1140 Vienna, Austria
}

(Received 30 October 2007 - Revised 24 June 2008 - Accepted 26 June 2008 - First published online 7 August 2008)

The impact of nutrition on the epigenetic machinery has increasingly attracted interest. The aim of the present study was to demonstrate the effects of various diets on methylation and gene expression. The antioxidative enzyme mitochondrial superoxide dismutase (MnSOD) was chosen as the model system because epigenetic regulation has been previously shown in cell lines for this gene. Promoter methylation and gene expression of MnSOD in buccal swabs from three sample groups were analysed. The three groups included: (1) forty vegetarians (aged 20-30 years); (2) agematched omnivores; (3) elderly omnivores (aged $>85$ years). A 3-fold increase in the expression of the MnSOD gene was associated with decreased $\mathrm{CpG}$ methylation of the analysed promoter region in the vegetarian group compared with the age-matched omnivores group. Expression and promoter methylation of the MnSOD gene in elderly omnivores showed no significant differences compared with younger omnivores. In accordance with previous findings in various tissues, DNA global methylation was found to be significantly higher ( $30 \%)$ in buccal swabs of younger subjects (independent of the diet), than in those of elderly omnivores. In the control experiment which was designed to verify the findings of the human buccal swab studies, the Caco-2 cell line was treated with zebularine. Results of the control study showed a 6-fold increase of MnSOD expression, an approximately $40 \%$ decreased methylation of specified CpG in the MnSOD promoter and a $50 \%$ reduction of global DNA methylation. These results indicate that diet affects the epigenetic regulation of human MnSOD.

Mitochondrial superoxide dismutase: Epigenetic regulation: Buccal mucosa: Vegetarian diet

The impact of nutrition on the epigenetic machinery ${ }^{(1-3)}$ has increasingly attracted interest. There is increasing evidence of the determinant role of the environment, including nutrition, on the expression of many genes related to health status ${ }^{(4-8)}$. Many environmental factors, for example, irradiation or toxins, are known to induce signalling pathways that provoke oxidative stress in tissues. These same pathways are associated with the aetiology and early pathology of many chronic diseases or ageing ${ }^{(9,10)}$.

Hypermethylation of $\mathrm{CpG}$ islands located in promoter regions of genes has been shown to alter gene expression ${ }^{(11,12)}$. DNA methylation is mediated by DNA methyltransferases (DNMT). Inhibitors such as zebularine restore expression of methylated genes by inhibition of the methyltransferases ${ }^{(13)}$. Additional mechanisms at the histone ${ }^{(14)}$ and small interfering $\mathrm{RNA}^{(15)}$ levels also contribute to the epigenetic regulatory system.

Epidemiological data suggest that epigenetic mechanisms are responsible for a correlation between parental nutrition and the risk of progeny developing certain diseases ${ }^{(16,17)}$. Experiments utilising the agouti mouse model show a transgenerational alteration of the mouse phenotype by hypermethylation of the agouti gene due to methyl donor-rich diets ${ }^{(18)}$.

Several dietary compounds are implicated in the regulation of the DNA-methylation pathway. Vitamin $\mathrm{B}_{12}$ is a cofactor in the folate-mediated remethylation of homocysteine to methionine, which is further activated to $S$-adenosylmethionine (SAM), the methyl donor for DNA methylation. SAM converts to $S$-adenosylhomocysteine (SAH) after DNA methylation. Reversible hydrolysis of SAH to homocysteine completes the cycle. Under conditions of elevated homocysteine concentrations, this reaction is reversed resulting in an increased concentration of the potent SAM-inhibitor SAH. Deficiency in vitamin $B_{12}$ leads to an accumulation of serum homocysteine ${ }^{(19)}$. The vegetarian diet is low in vitamin $B_{12}$, thereby reducing the remethylation of homocysteine and resulting in low methionine content ${ }^{(19)}$, which may reduce DNA-methylation machinery in vegetarians. Studies conducted at our Nutrition Department at the University of Vienna have previously demonstrated that vegetarians displayed decreased vitamin $B_{12}$ and enhanced homocysteine plasma concentrations compared with omnivores ${ }^{(20)}$.

Abbreviations: DNMT, DNA methyltransferase; G6PD, glucose-6-phosphate dehydrogenase; MnSOD, mitochondrial superoxide dismutase; SAH, S-adenosylhomocysteine; SAM, $S$-adenosylmethionine; TA, telomerase activity.

* Corresponding author: Dr Alexander G. Haslberger, fax +43 1 8795896, email alexander.haslberger@univie.ac.at 
DNA methylation of $\mathrm{CpG}$ of specific genes needs to be differentiated from global DNA methylation because during ageing the DNA total methylation level declines, whereas some gene promoters tend to be hypermethylated ${ }^{(21-23)}$. Genes that change methylation status with age are tissue specific ${ }^{(21)}$. This process is also described in the pathology of many cancers ${ }^{(22)}$ and may be attributed to a decreased expression of the global methylation-related DNMT1 and an increased expression of the specific methylation-related DNMT3b during ageing ${ }^{(9)}$.

Mitochondrial superoxide dismutase (MnSOD) is an antioxidant enzyme and converts superoxide radicals $\left(\mathrm{O}^{-}\right)$, which are highly reactive and damaging to cellular structures, to $\mathrm{H}_{2} \mathrm{O}_{2}^{(24)}$. Reactive oxygen species are known to contribute to many pathological mechanisms and ageing, but also have fundamental beneficial roles, for example, in the innate immune response ${ }^{(25)}$. The cancer-promoting effects of superoxide radicals have been linked to experimental data demonstrating changes in the tumour-suppressor activity of $\mathrm{MnSOD}^{(26)}$. Close regulation of such proteins is essential. Hereditary influences $^{(24,27)}$ but also epigenetic regulation ${ }^{(28)}$ are proposed for the expression of the MnSOD gene.

The present paper focuses on the analysis of epigenetic regulation of the MnSOD gene. It describes the effect of different diets and age on expression of the MnSOD gene and methylation of its promoter as well as the affects on global methylation in comparison with a cell model. In addition, we analysed the expression of telomerase because its expression is associated with ageing in several tissues ${ }^{(29)}$. The findings demonstrate that diet may impact on epigenetic regulation of MnSOD, the consequences of which should be further examined.

\section{Experimental methods}

\section{Groups and sample collection}

Buccal swabs from three subject groups (sex matched) were collected and stored at $-20^{\circ} \mathrm{C}$ in PBS. The subject groups consisted of: (1) ovo-lacto vegetarians including those who consumed fish (aged 20-30 years); (2) young omnivores (aged 20-30 years); (3) elderly omnivores (aged $>85$ years). The reliability and reproducibility of buccal mucosa for the investigation of gene expression and methylation has previously been established ${ }^{(2,30)}$. The volunteers were selected after the evaluation of a questionnaire characterising nutritional habits, food preferences and food intake, daily liquid intake, alcohol intake, vitamin supplementation, smoking, drug intake, and health status. Only subjects who had consumed an ovo-lacto vegetarian diet for at least 5 years were admitted to the study. Volunteers who reported vitamin supplementation, a high alcohol intake, or smoking were excluded from the study. Written formal consent was obtained from all subjects. The study protocol is covered by an agreement of the ethical committee of the city of Vienna.

\section{Cell line and treatment with methyltransferase inhibitor}

The human endodermal carcinoma cell line Caco-2 was grown in Roswell Park Memorial Institute (RPMI) 1640 media supplemented with $4 \mathrm{~mm}$-glutamine, $10 \%$ heat-inactivated fetal bovine serum, and 100 units each of streptomycin and penicillin. For inhibition of DNMT1, cells were treated with zebularine at a concentration of $250 \mu \mathrm{mol} / 1$ for $48 \mathrm{~h}$. Cells were washed twice with cooled $\mathrm{PBS}\left(4^{\circ} \mathrm{C}\right)$ before nucleotide extraction.

\section{Genomic DNA isolation and bisulfite modification}

DNA was isolated from cells using a DNA Isolation Kit (Qiagen, Hilden, Germany) and bisulfite conversion of unmethylated cytosines was performed using the Epitect Bisulfite Kit (Qiagen). Both kits were used according to the manufacturer's instructions.

\section{Polymerase chain reaction of bisulfite-treated DNA}

Two sequential PCR were used to amplify the modified DNA fragments of interest. The primers for the first PCR were: sense primer 5'-GTA TTT TTA GGG G[C/T]G GAT $[\mathrm{C} / \mathrm{T}] \mathrm{GG}$ AGG TAG GGT TT- $3^{\prime}$ and antisense primer 5'-CCA AAC CC[A/G] ATA C[A/G]A CCA CTA TC[A/G] CCA TTA $\mathrm{C}-3^{\prime}$. The primers for the second PCR were: sense primer $5^{\prime}$-GGG T[C/T]G TAT TAA TTT TA[C/T] GGG GGT AGG GGT-3' and antisense primer 5'-AAC CCC TTA CCC CTT AAA AC[A/G] TAA CC[A/G] AAT CCC-3' (reference sequence: GenBank L34157). Conditions for the first PCR cycling were: $95^{\circ} \mathrm{C}$ for $3 \mathrm{~min}$ followed by thirty-five cycles at $94^{\circ} \mathrm{C}$ for $30 \mathrm{~s}$, annealing at $55^{\circ} \mathrm{C}$ for $1 \mathrm{~min}$ and extension at $72^{\circ} \mathrm{C}$ for $2 \mathrm{~min}$; and finally $7 \mathrm{~min}$ at $72^{\circ} \mathrm{C}$. The second PCR was performed under the same conditions as the first run with the exception of the annealing temperature which was modified to $57^{\circ} \mathrm{C}$. The PCR reaction of $25 \mu \mathrm{l}$ contained $12.5 \mu \mathrm{l}$ of $2 \times$ PCR master mix (Biotools, Madrid, Spain), $1 \mu$ l of each primer at a concentration of $30 \mathrm{pmol} / \mu \mathrm{l}$ and $2 \mu \mathrm{l}$ template. The amplified DNA fragments of intended size were purified by agarose-gel extraction with the QIAquick Gel Extraction Kit (Qiagen) and subsequently directly sequenced by an ABI sequencing system (Applied Biosystems, Foster City, CA, USA). Gene expression-related AP-2 and SP-1 binding sites ${ }^{(28,31,32)}$ were selected for detailed methylation quantification. No differences were seen between sequencing of cloned samples compared with directly sequenced samples.

\section{Analysis of mitochondrial superoxide dismutase gene expression}

Total mRNA was extracted from cells using the mRNA Isolation Kit (Roche, Mannheim, Germany) and reverse transcribed using the single-strand cDNA Synthesis Kit (Roche, Mannheim, Germany). Gene expression was performed by real-time TaqMan PCR using the Corbett Rotor-Gene 3000. The target mRNA expression was normalised to the glucose6-phosphate dehydrogenase (G6PD) expression. The following thermocycling conditions were selected for all genes: $95^{\circ} \mathrm{C}$ for $3 \mathrm{~min}$ and forty-five cycles of $95^{\circ} \mathrm{C}$ for $30 \mathrm{~s}$ and $67^{\circ} \mathrm{C}$ for $45 \mathrm{~s}$. Real-time PCR were set up in $10 \mu \mathrm{l}$ final volumes. Optimum reaction conditions were obtained for the MnSOD gene with $5 \mu$ l of $2 \times$ PCR master mix (Quantimix Easy Probes Kit; Biotools, Madrid, Spain), $1 \mu \mathrm{l}(8 \mathrm{pmol} / \mu \mathrm{l})$ of each primer and $1 \mu \mathrm{l}(2 \mathrm{pmol} / \mu \mathrm{l})$ probe and for the G6PD 
gene with $5 \mu \mathrm{l}$ of $2 \times$ PCR master mix, $1 \mu \mathrm{l}(10 \mathrm{pmol} / \mu \mathrm{l})$ of each primer and $1 \mu \mathrm{l}(2.4 \mathrm{pmol} / \mu \mathrm{l})$ probe. Finally, $2 \mu \mathrm{l}$ template cDNA was added to the reaction mixture. The primers and probes were as follows: MnSOD primer sense $5^{\prime}$-AAG GGA GAT GTT ACA GCC CAG ATA-3', MnSOD primer antisense $5^{\prime}$-TCC AGA AAA TGC TAT GAT TGA TAT GAC- $3^{\prime}$, MnSOD probe $5^{\prime}$-CCA CCA TTG AAC TTC AGT GCA GGC TG-3', G6PD primer sense 5'-ATC GAC CAC TAC CTG GGC AA-3', G6PD primer antisense 5'-TTC TGC ATC ACG TCC CGG A-3' and G6PD probe $5^{\prime}$-AAG ATC CTG TTG GCA AAT CTC AGC ACC A-3'. All probes were marked with flavin-adenine mononucleotide as the fluorophor and black hole quencher (BHQ) 1 as the quencher.

\section{DNA total methylation analysis}

DNA global methylation was analysed by the Methylamp ${ }^{\text {TM }}$ Global DNA Methylation Quantification Kit (Epigentek, New York, USA) according to the manufacturer's instructions. DNA methylation status was compared with an artificially fully methylated DNA standard.

\section{Relative telomerase activity}

The relative telomerase activity (TA) was determined by the real-time quantitative telomeric repeat amplification protocol (RTQ-TRAP) assay ${ }^{(33)}$. For Sybr Green real-time PCR the following primers at a concentration of $10 \mathrm{pmol} / \mu \mathrm{l}$ were used: sense primer $5^{\prime}$-AAT CCG TCG AAG AGT T-3' and antisense primer $5^{\prime}$-GCG CGG CTT ACT AAC C-3'. The reactions were set up with $5 \mu$ l Sybr Green Master Mix (Biotools, Madrid, Spain), $1 \mu$ l of each primer and 1-3 $\mu$ l of sample, depending on the calculated protein concentration. Cycling conditions were: $3 \mathrm{~min}$ at $95^{\circ} \mathrm{C}$ followed by fifty cycles of $20 \mathrm{~s}$ at $95^{\circ} \mathrm{C}, 30 \mathrm{~s}$ at $50^{\circ} \mathrm{C}$ and $90 \mathrm{~s}$ at $72^{\circ} \mathrm{C}$.

\section{Results}

Role of diet on methylation and expression of mitochondrial superoxide dismutase

When gene expression and MnSOD promoter methylation status of human buccal swabs of subjects consuming two different diet forms and zebularine-treated or -untreated Caco-2 endodermal cells were analysed, the results suggested that MnSOD expression is epigenetically regulated by diet or factors associated with diet choice.

CpG methylation. Fig. 1 (b) illustrates the reduced methylation patterns in the MnSOD promoter region in cells of buccal swabs sampled from the vegetarian group. Analysis of bisulfite-treated DNA using genomic sequencing of the promoter region by the ABI Prism system indicated an approximately 30-40\% methylation of the relevant CpG (Fig. 1 (a)). No significant difference in methylation of the MnSOD region was observed when buccal swabs of groups of elderly $(>85$ years) and young (20-30 years) subjects consuming the same diet were compared.
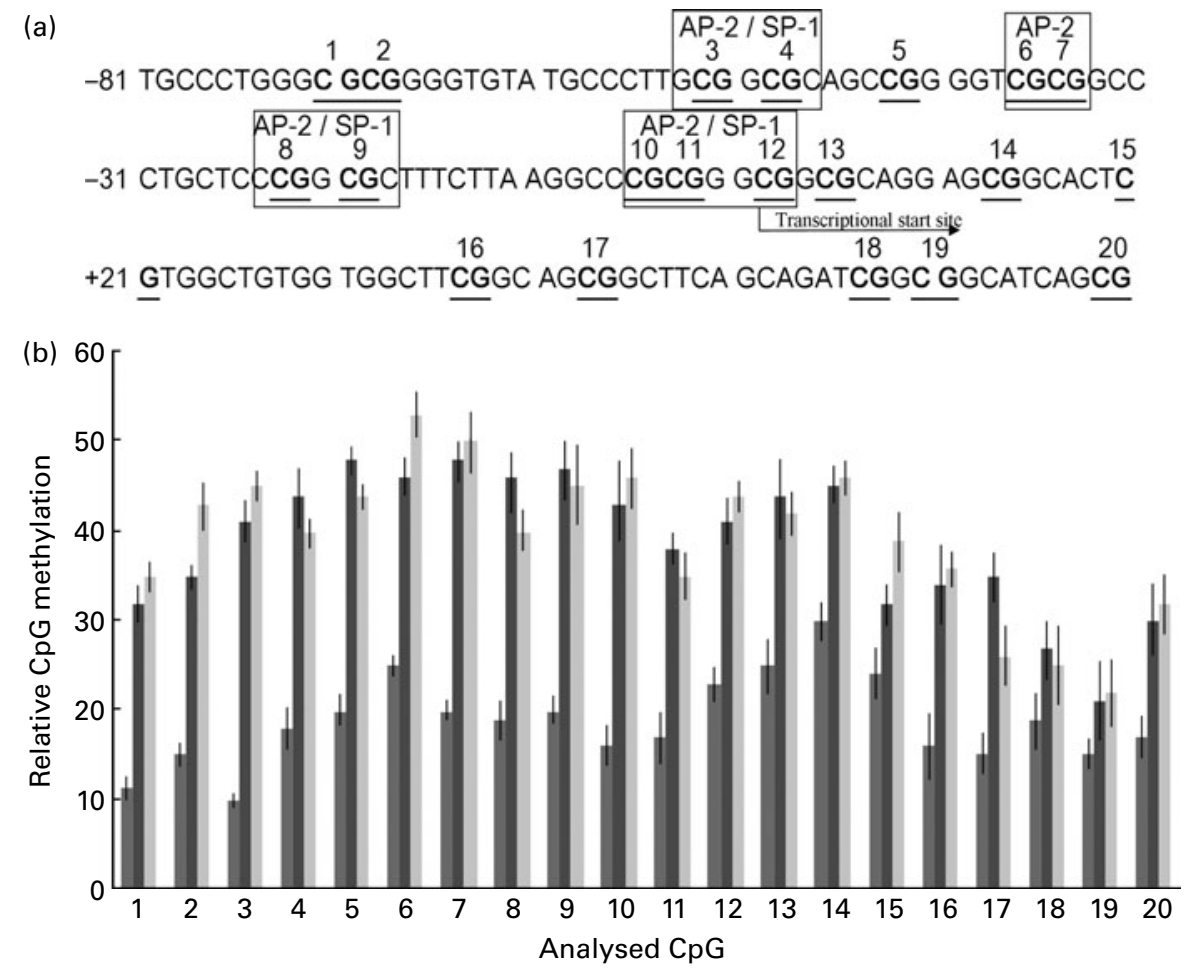

Fig. 1. (a) Mitochondrial superoxide dismutase promoter region showing CpG, activating protein (AP)-2 and stimulatory protein (SP)-1 binding sites. (b) Percentage of methylation of twenty CpG ( $\pm 10 \%$; shown in bold and numbered in (a)) in vegetarian subjects ( $\square$ ), and young ( $\square$ ) and elderly ( $\square$ ) omnivores. Values are means, with standard deviations represented by vertical bars. Relative CpG methylation refers to the proportion of cytosine-thymine signals at these sites in the electropherograms. 
Gene expression. Expression of MnSOD was found to be significantly higher in the group of forty vegetarians compared with the group of forty age-matched omnivores. Compared with the expression of G6PD, vegetarians showed a 3.2 (SD 0.7)-fold $(P<0.05)$ increase in MnSOD mRNA expression. No significant difference in MnSOD gene expression was observed between the group of forty elderly subjects ( $>85$ years) and the group of forty subjects aged 20-30 years, both of whom adhered to a conventional middle European diet.

\section{Effect of age on DNA global methylation}

DNA global methylation. DNA global methylation of about $1.4 \%$ was detected in the buccal mucosa samples of young omnivores. No significant difference in DNA global methylation levels could be seen in the vegetarian subject group. However, reduced genome-wide methylation (by about $4 \%$; $P<0.05$ ) was found in the elderly subject group (Fig. 2 (c)).

Telomerase activity. The relative TA was determined by the real-time quantitative telomeric repeat amplification protocol (RTQ-TRAP) assay. Significant $(P<0.05)$ differences were observed between young and elderly subjects, independent of diet. Vegetarians showed a TA of 0.79 (SD 0.97), young omnivores showed a TA of 0.80 (SD 0.02) and elderly omnivores showed a TA of $0 \cdot 15$ (SD 0.01).

\section{Effect of zebularine on epigenetic regulation of the} mitochondrial superoxide dismutase gene

Methyltransferase inhibition results in gene-specific and global hypomethylation in Caco-2 cells. Zebularine treatment caused demethylation of $\mathrm{CpG}$ in the analysed MnSOD promoter region of Caco-2 cells. Analysis of bisulfite-treated DNA using genomic sequencing of the promoter region by $\mathrm{ABI}$ sequencing indicated an approximately 60-70\% methylation of the relevant $\mathrm{CpG}$ which was reduced to about 30-40\% methylation due to zebularine treatment (data not shown).

When the DNA global methylation was measured by ELISA, the level in zebularine-treated Caco-2 cells was decreased by approximately $30 \%$ compared with an artificially fully methylated DNA standard.

Methyltransferase inhibition induces gene expression in Caco-2 cells. Gene expression (Fig. 2 (a)) and methylation status of the MnSOD promoter region was analysed in Caco-2 cells after incubation with the methyltransferase inhibitor zebularine for $48 \mathrm{~h}$. Several concentrations and incubation times were tested (data not shown). A concentration of zebularine at $250 \mu \mathrm{mol} / 1$ for $48 \mathrm{~h}$ showed the greatest DNMT1 inhibition. The expression of MnSOD in zebularine-treated cells increased 6.3 (SD 0.3)-fold $(P<0.05)$, referenced to G6PD mRNA expression levels. The results obtained for MnSOD promoter methylation and gene expression in the Caco-2 cell-line experiments agree with previously reported observations from a multiple myeloma cell line ${ }^{(28)}$. Analysis of methylation of $\mathrm{CpG}$ focused on those $\mathrm{CpG}$ that are situated in the AP-2 and SP-1 transcription factor-binding sites ${ }^{(28,31,32)}$.
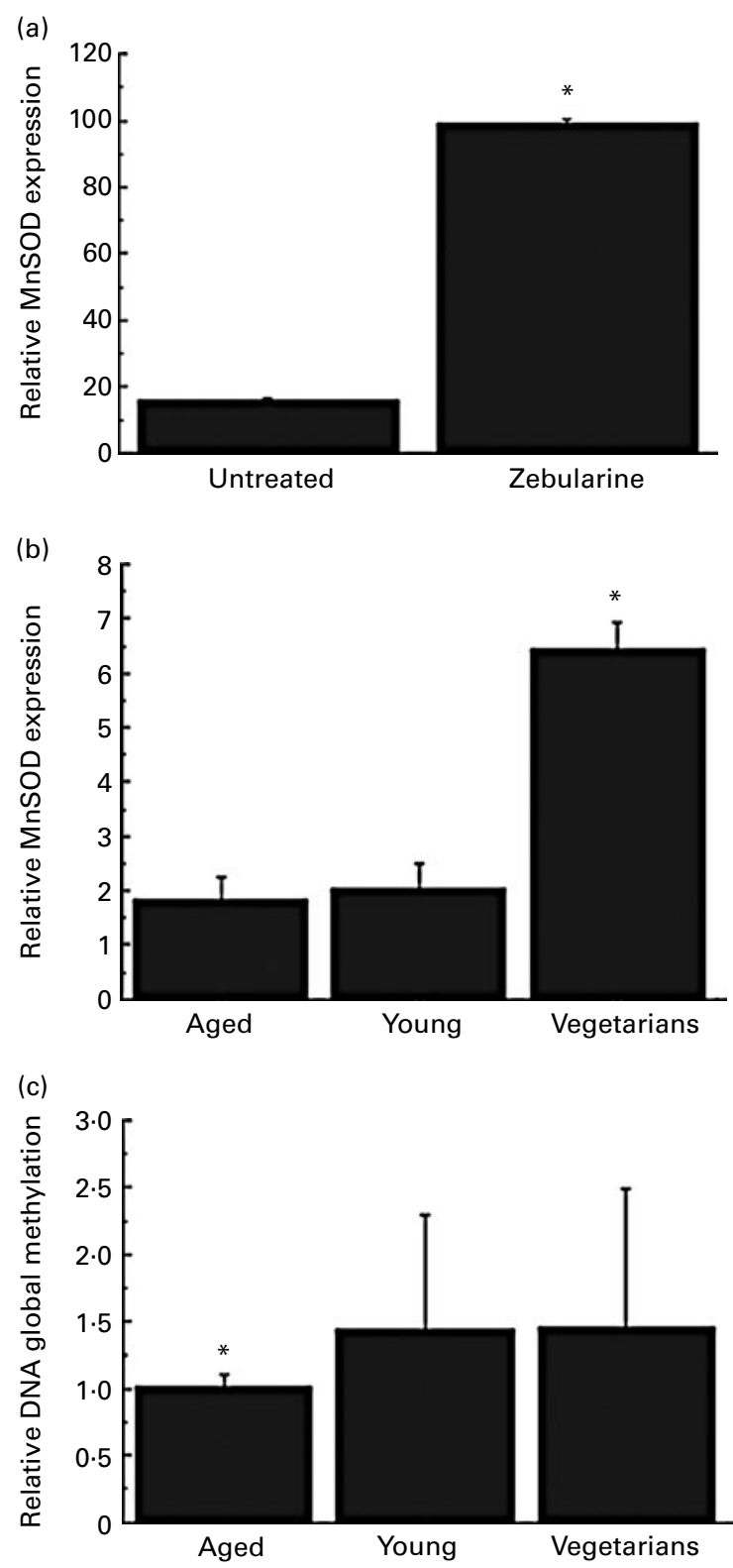

Fig. 2. (a) Increase of mitochondrial superoxide dismutase (MnSOD) gene expression after a $48 \mathrm{~h}$ zebularine treatment in the endodermal Caco-2 cell line. ${ }^{*} \mathrm{MnSOD}$ expression increased in zebularine-treated cells by 6.3 (SD 0.3)-fold compared with zebularine-untreated cells $(P<0.05)$. (b) Relative MnSOD gene expression in elderly (1.81 (SD 0.7)) and young (2.02 (SD 0.8)) omnivores and in vegetarians (6.46 (SD 0.7)). MnSOD gene expression is referenced to glucose-6-phosphate dehydrogenase expression levels. *Vegetarians showed a 3.2 -fold $(P<0.05)$ increase in MnSOD expression compared with young subjects and a 3.6 -fold $(P<0.05)$ increase compared with elderly omnivores. (c) DNA global methylation in the omnivorous and vegetarian (1.44 (SD 0.64)) diet groups, groups of elderly (>85 years; 1.02 (SD $0.05)$ ) and young omnivores (20-30 years; 1.45 (SD 0.53$)$ ), in percentage of totally methylated control DNA. *DNA global methylation was significantly higher $(30 \%)$ in the younger subjects (vegetarian and omnivorous) than in the elderly omnivores $(P<0.05)$. Values are means, with standard deviations represented by vertical bars.

\section{Discussion}

The influence of environmental factors and the role of nutrition on the epigenetic regulation of gene expression are important topics in the understanding of gene expression and 
prevention of diseases. Based on results of in vitro studies, we investigated the methylation-dependent epigenetic regulation of the MnSOD gene as well the DNA total methylation in mucosal swabs of subjects consuming different diets and of different ages. Results of the present study demonstrated a significantly higher expression of MnSOD mRNA in young vegetarian subjects (20-30 years) compared with omnivores of the same age. Higher MnSOD expression correlated with a $\mathrm{CpG}$ demethylation in the promoter region of the gene in the vegetarian group. Furthermore, our findings show significant differences in the DNA global methylation and TA between young and elderly subjects.

Previous studies analysing the B-vitamin status of comparable groups of vegans, vegetarians and omnivores, conducted by our department in Austria, showed a higher dietary supply of folate and a lower dietary supply of cobalamin for the vegetarian and vegan group. A correlation between plasma folate and vitamin $B_{12}$ values was seen and study findings showed that the vegetarian and vegan group had the highest plasma homocysteine concentrations ${ }^{(20)}$. DNA hypomethylation due to high homocysteine levels has been reported in vitro and in vivo ${ }^{(34,35)}$. Several other studies support these observations and indicate a lower intake of methionine in vegetarians $(19,20,36)$. These characteristics of the vegetarian diet may explain the decreased activity of the DNA-methylation pathway resulting in a decreased methylation of the MnSOD gene.

Geisel et al. ${ }^{(19)}$ also compared vegetarians and omnivores and observed an inverse correlation between SAH concentrations and DNA global methylation levels in blood. But, Geisel et al. were unable to correlate the degree of $\mathrm{CpG}$ methylation of the promoter of the $p 66 S h c$ gene (involved in oxidative stress) and homocysteine, SAM or SAH levels. These different methylation results seen for the MnSOD and p66Shc promoter region might be explained by the activity of different DNMT for both genes. Also, no correlation between homocysteine concentrations and the degree of DNA global methylation was found by Geisel et al. ${ }^{(19)}$. They suggested that the generation of SAM may be critical in vegetarians because formation of the precursor methionine is decreased by the disturbed remethylation of homocysteine due to the lower vitamin $B_{12}$ supply.

However, vegetarians display a tendency for higher intakes and serum concentrations of the methyl donor folate $^{(20)}$, and human, animal and in vitro studies suggest that folate-dependent DNA methylation is highly complex, gene and site specific ${ }^{(37-40)}$. In addition, the vegetarian diet is characterised by a higher intake in secondary dietary compounds such as diallyl sulfide ${ }^{(9)}$, an organosulfur compound found in garlic, genistein, the main flavonoid in soya ${ }^{(4)}$, and vitamin $\mathrm{D}_{3}$ or all-trans-retinoic-acid ${ }^{(41)}$ which have been shown to influence DNA methylation by altering histones and chromatin structure. Analysis of the impact of nutrition on gene regulation therefore needs to consider complex and multifactorial elements.

A higher MnSOD gene expression in vegetarians was seen in the present study. Thus, a better defence against superoxide radicals might be expected as a consequence of a vegetarian diet. Because of this activity and its role in the regulation of apoptosis ${ }^{(42)}$, MnSOD was suggested as a tumour-suppressor gene ${ }^{(26)}$. Epidemiological data suggest that vegetarians show lower rates of several types of cancer and chronic cardiovascular diseases compared with omnivores $^{(43-45)}$. So far, these findings were explained by a higher intake of antioxidant vitamins, $\mathrm{Cu}$ and secondary dietary compounds ${ }^{(46,47)}$. With the results of the present study, we suggest that the higher protection against chronic diseases in vegetarians may be explained by both epigenetic and chemico-physiological aspects.

Findings of the present study showed a significantly lower DNA global methylation status as well as TA in elderly omnivores. No differences in DNA global methylation were seen between vegetarian subjects and age-matched omnivores. Several alterations, such as global hypomethylation, $\mathrm{CpG}$ island hypermethylation or telomere shortening develop progressively as a result of ageing ${ }^{(23)}$. Methylation of $\mathrm{CpG}$ islands in non-malignant tissues increases but the total number of methylated cytosine residues decreases with age $\mathrm{e}^{(48,49)}$.

Age-dependent chromosomal instability and DNA doublestrand breaks are mechanisms that have been demonstrated in laboratory rats fed hypomethylated diets throughout their lifespan as well as in postmenopausal women with methyl donor-deficient diets ${ }^{(50)}$. This chromosomal instability promotes the progressive methylation of individual genes during ageing ${ }^{(21)}$. Highly differentiated methylation of the same gene has been observed in various tumour tissues ${ }^{(11)}$.

The present study has demonstrated that nutritional stimuli contribute to epigenetic regulation of MnSOD in buccal mucosa. These results could provide a foundation for targeted dietary approaches ${ }^{(50)}$ designed to alleviate or minimise the consequences of environmental and toxic influences on DNA methylation or other epigenetic mechanisms. In order to better understand the implications of diet, the influence of nutrients on DNA methylation enzymes and histone modification needs to be further analysed.

\section{Acknowledgements}

The present study was supported by the Federal Ministry of Health, Family and Youth. A. G. H. and R. T. designed the study. R. T. also performed the data analysis. H. K. and P. R. contributed to the drafting of the paper. The authors declare that they have no conflicts of interest.

We acknowledge critical reading by Dr Franz Varga, Elizabeth McBride and Professor Ibrahim Elmadfa.

\section{References}

1. Ahmed FE (2007) Colorectal cancer epigenetics: the role of environmental factors and the search for molecular biomarkers. J Environ Sci Health C Environ Carcinog Ecotoxicol Rev 25, 101-154.

2. Johanning GL, Heimburger DC \& Piyathilake CJ (2002) DNA methylation and diet in cancer. J Nutr 132, 3814S-3818S.

3. Liddle RA \& Jirtle RL (2006) Epigenetic silencing of genes in human colon cancer. Gastroenterology 131, 960-962.

4. Dolinoy DC, Weidman JR, Waterland RA \& Jirtle RL (2006) Maternal genistein alters coat color and protects Avy mouse offspring from obesity by modifying the fetal epigenome. Environ Health Perspect 114, 567-572.

5. Haslberger A, Varga F \& Karlic H (2006) Recursive causality in evolution: a model for epigenetic mechanisms in cancer development. Med Hypotheses 67, 1448-1454. 
6. Jirtle RL \& Skinner MK (2007) Environmental epigenomics and disease susceptibility. Nat Rev Genet 8, 253-262.

7. Lillycrop KA, Slater-Jefferies JL, Hanson MA, Godfrey KM, Jackson AA \& Burdge GC (2007) Induction of altered epigenetic regulation of the hepatic glucocorticoid receptor in the offspring of rats fed a protein-restricted diet during pregnancy suggests that reduced DNA methyltransferase-1 expression is involved in impaired DNA methylation and changes in histone modifications. Br J Nutr 97, 1064-1073.

8. Tang WY \& Ho SM (2007) Epigenetic reprogramming and imprinting in origins of disease. Rev Endocr Metab Disord 8, 173-182.

9. Mathers JC (2006) Nutritional modulation of ageing: genomic and epigenetic approaches. Mech Ageing Dev 127, 584-589.

10. Olinski R, Siomek A, Rozalski R, Gackowski D, Foksinski M, Guz J, Dziaman T, Szpila A \& Tudek B (2007) Oxidative damage to DNA and antioxidant status in aging and age-related diseases. Acta Biochim Pol 54, 11-26.

11. Esteller M, Corn PG, Baylin SB \& Herman JG (2001) A gene hypermethylation profile of human cancer. Cancer Res $\mathbf{6 1}$, 3225-3229.

12. Wade PA (2001) Methyl CpG binding proteins: coupling chromatin architecture to gene regulation. Oncogene 20, 3166-3173.

13. Zhou L, Cheng X, Connolly BA, Dickman MJ, Hurd PJ \& Hornby DP (2002) Zebularine: a novel DNA methylation inhibitor that forms a covalent complex with DNA methyltransferases. J Mol Biol 321, 591-599.

14. Cheung P \& Lau P (2005) Epigenetic regulation by histone methylation and histone variants. Mol Endocrinol 19, $563-573$

15. Baulcombe DC (2006) Short silencing RNA: the dark matter of genetics? Cold Spring Harb Symp Quant Biol 71, 13-20.

16. Kaati G, Bygren LO \& Edvinsson S (2002) Cardiovascular and diabetes mortality determined by nutrition during parents' and grandparents' slow growth period. Eur J Hum Genet 10, $682-688$

17. Kaati G, Bygren LO, Pembrey M \& Sjostrom M (2007) Transgenerational response to nutrition, early life circumstances and longevity. Eur J Hum Genet 15, 784-790.

18. Waterland RA \& Jirtle RL (2003) Transposable elements: targets for early nutritional effects on epigenetic gene regulation. Mol Cell Biol 23, 5293-5300.

19. Geisel J, Schorr H, Bodis M, Isber S, Hübner U, Knapp JP, Obeid R \& Herrmann W (2005) The vegetarian lifestyle and DNA methylation. Clin Chem Lab Med 43, 1164-1169.

20. Majchrzak D, Singer I, Männer M, Rust P, Genser D, Wagner KH \& Elmadfa I (2006) B-vitamin status and concentrations of homocysteine in Austrian omnivores, vegetarians and vegans. Ann Nutr Metab 50, 485-491.

21. Agrawal A, Murphy RF \& Agrawal DK (2007) DNA methylation in breast and colorectal cancers. Mod Pathol 20, 711-721.

22. Fraga MF, Agrelo R \& Esteller M (2007) Cross-talk between aging and cancer: the epigenetic language. Ann N Y Acad Sci 1100, 60-74.

23. Fraga MF \& Esteller M (2007) Epigenetics and aging: the targets and the marks. Trends Genet 23, 413-418.

24. Han J, Colditz GA \& Hunter DJ (2007) Manganese superoxide dismutase polymorphism and risk of skin cancer (United States). Cancer Causes Control 18, 79-89.

25. Marcinkiewicz J, Ciszek M, Bobek M, Strus M, Heczko PB, Kurnyta M, Biedroń R \& Chmielarczyk A (2007) Differential inflammatory mediator response in vitro from murine macrophages to lactobacilli and pathogenic intestinal bacteria. Int $J$ Exp Pathol 88, 155-164.

26. Tang C, Ang BT \& Pervaiz S (2007) Cancer stem cell: target for anti-cancer therapy. FASEB $J \mathbf{2 1}, 3777-3785$.
27. Lightfoot TJ, Skibola CF, Smith AG, Forrest MS, Adamson PJ, Morgan GJ, Bracci PM, Roman E, Smith MT \& Holly EA (2006) Polymorphisms in the oxidative stress genes, superoxide dismutase, glutathione peroxidase and catalase and risk of non-Hodgkin's lymphoma. Haematologica 91, $1222-1227$.

28. Hodge DR, Peng B, Pompeia C, Thomas S, Cho E, Clausen PA, Marquez VE \& Farrar WL (2005) Epigenetic silencing of manganese superoxide dismutase (SOD-2) in KAS 6/1 human multiple myeloma cells increases cell proliferation. Cancer Biol Ther 4, 585-592.

29. Hornsby PJ (2007) Telomerase and the aging process. Exp Gerontol 42, 575-581.

30. Hitchins M, Williams R, Cheong K, et al. (2005) MLH1 germline epimutations as a factor in hereditary nonpolyposis colorectal cancer. Gastroenterology 129, 1392-1399.

31. Hodge DR, Xiao W, Peng B, Cherry JC, Munroe DJ \& Farrar WL (2005) Enforced expression of superoxide dismutase 2/manganese superoxide dismutase disrupts autocrine interleukin-6 stimulation in human multiple myeloma cells and enhances dexamethasone-induced apoptosis. Cancer Res $\mathbf{6 5}$, $6255-6263$

32. Xu Y, Porntadavity S \& St Clair DK (2002) Transcriptional regulation of the human manganese superoxide dismutase gene: the role of specificity protein $1(\mathrm{Sp} 1)$ and activating protein-2 (AP-2). Biochem J 362, 401-412.

33. Hou M, Xu D, Bjorkholm M \& Gruber A (2001) Realtime quantitative telomeric repeat amplification protocol assay for the detection of telomerase activity. Clin Chem 47, 519-524.

34. Jamaluddin MD, Chen I, Yang F, Jiang X, Jan M, Liu X, Schafer AI, Durante W, Yang X \& Wang H (2007) Homocysteine inhibits endothelial cell growth via DNA hypomethylation of the cyclin A gene. Blood 110, 3648-3655.

35. Jiang Y, Sun T, Xiong J, Cao J, Li G \& Wang S (2007) Hyperhomocysteinemia-mediated DNA hypomethylation and its potential epigenetic role in rats. Acta Biochim Biophys Sin (Shanghai) 39, 657-667.

36. Mann NJ, Li D, Sinclair AJ, Dudman NP, Guo XW, Elsworth GR, Wilson AK \& Kelly FC (1999) The effect of diet on plasma homocysteine concentrations in healthy male subjects. Eur $J$ Clin Nutr 53, 895-899.

37. Cravo M, Fidalgo P, Pereira AD, Gouveia-Oliveira A, Chaves P, Selhub J, Mason JB, Mira FC \& Leitao CN (1994) DNA methylation as an intermediate biomarker in colorectal cancer: modulation by folic acid supplementation. Eur J Cancer Prev 3, 473-479.

38. Kim YI (2004) Folate and DNA methylation: a mechanistic link between folate deficiency and colorectal cancer? Cancer Epidemiol Biomarkers Prev 13, 511-519.

39. Kim YI, Baik HW, Fawaz K, Knox T, Lee YM, Norton R, Libby E \& Mason JB (2001) Effects of folate supplementation on two provisional molecular markers of colon cancer: a prospective, randomized trial. Am J Gastroenterol 96, 184-195.

40. Rampersaud GC, Kauwell GP, Hutson AD, Cerda JJ \& Bailey LB (2000) Genomic DNA methylation decreases in response to moderate folate depletion in elderly women. Am J Clin Nutr 72, 998-1003.

41. Krawczyk B \& Fabianowska-Majewska K (2006) Alteration of DNA methylation status in K562 and MCF-7 cancer cell lines by nucleoside analogues. Nucleosides Nucleotides Nucleic Acids 25, 1029-1032.

42. Kinscherf R, Claus R, Wagner M, et al. (1998) Apoptosis caused by oxidized LDL is manganese superoxide dismutase and p53 dependent. FASEB $J$ 12, 461-467.

43. Sanjoaquin MA, Appleby PN, Thorogood M, Mann JI \& Key TJ (2004) Nutrition, lifestyle and colorectal cancer 
incidence: a prospective investigation of 10998 vegetarians and non-vegetarians in the United Kingdom. Br J Cancer 90, $118-121$

44. Thorogood M, Mann J, Appleby P \& McPherson K (1994) Risk of death from cancer and ischaemic heart disease in meat and non-meat eaters. $\mathrm{Br}$ Med J 308, 1667-1670.

45. Mills PK, Beeson WL, Phillips RL \& Fraser GE (1994) Cancer incidence among California Seventh-Day Adventists, 1976-1982. Am J Clin Nutr 59, Suppl. 5, 1136S-1142S.

46. Haldar S, Rowland IR, Barnett YA, Bradbury I, Robson PJ, Powell J \& Fletcher J (2007) Influence of habitual diet on antioxidant status: a study in a population of vegetarians and omnivores. Eur J Clin Nutr 61, 1011-1022.

47. Rauma AL \& Mykkanen H (2000) Antioxidant status in vegetarians versus omnivores. Nutrition 16, 111-119.

48. Laird PW (2003) The power and the promise of DNA methylation markers. Nat Rev Cancer 3, 253-266.

49. Richardson BC (2002) Role of DNA methylation in the regulation of cell function: autoimmunity, aging and cancer. J Nutr 132, Suppl. 8, 2401S-2405S.

50. Van den Veyver IB (2002) Genetic effects of methylation diets. Аппи Rev Nutr 22, 255-282. 